\title{
RETRACTION
}

\section{Retraction to: Allogeneic hematopoietic stem cell transplantation for acquired aplastic anemia using cyclophosphamide and antithymocyte globulin: a single center experience}

S Ladeb, A Abdelkefi, L Torjman, H Ben Neji, A Lakhal, H Kaabi, L Ben Hamed, S Ennigrou, S Hmida,

T Ben Othman and A Ben Abdeladhim

Bone Marrow Transplantation (2014) 49, 468; doi:10.1038/bmt.2013.231; published online 13 January 2014

Retraction to: Bone Marrow Transplantation advance online publication, 27 July 2009; doi:10.1038/bmt.2009.175

Following the publication of a Notice of Concern, this article has been retracted. 